\title{
Estimation of the Residual Risk for the Transmission of HIV in Blood Donors from the Mountain Region of Santa Catarina
}

\author{
Celso Spada ${ }^{1}$, Marli Adelina Souza ${ }^{2,3}$ \\ and Arício Treitinger ${ }^{1}$
}

\begin{abstract}
Federal University of Santa Catarina'; Pharmacology Department ${ }^{2}$, Federal University of Santa Catarina; Regional Blood Center ${ }^{3}$, in Lages, Santa Catarina; Florianópolis, SC, Brazil
\end{abstract}

\begin{abstract}
The HIV, in hemotheraphy, may be transmitted by erythrocyte, platelets, crioprecipitated, frozen fresh plasma and possibly, by other blood components. Appropriate legislations for this new reality were elaborated normatizing the hemotheraphy practices in Brazil, creating a set of procedures and actions aiming at guaranteeing the quality of the blood, during, during the whole process. However, the residual risk remains, and it can be calculated as a product of the incidence and period of the immunological window. The objetive of the present study was to determine the rate of residual risk of the HIV blood transmission, in the blood donors from the Mountain Region of Santa Catarina. In order to calculate the residual risk of the HIV markers, 4,857 donors of repetition from the 24,969 individuals who donated blood from 2000 to 2003 were evaluated, and the results showed a serumconversion, in one case. The method used to calculate the residual risk followed the model of the immunological incidence window used by Schreiber (1996), in the USA. A estimate risk of 1:50,000 was verified. The case was considered as confirmed when one of the HIV, in the Hemocenter, is considered one of the HIV markers, in 1:50.000, which confirms the hypothesis that the new legislation related to the Blood National Politics, with the introduction of more sensible tests is decreasing the immunological window, diminishing the residual and, consequently, intensifying the transfusion security.

Key Words: HIV, blood donors, residual risk, transfusion security, immunological window.
\end{abstract}

The discovery of acquired immunodeficiency syndrome (AIDS) and its consequences have had a great impact on society, contributing to changing habits and customs, including those involving sexual behavior. Our hemotherapy institute made a review of criteria and indicators to use blood and hemoderivates [1], and appropriate legislation has been developed to adapt to this new reality, controlling hemotherapeutic processing in Brazil, establishing a set of procedures

Received on 25 June 2005; revised 14 October 2005.

Address for correspondence: Dr. Celso Spada. Federal University of Santa Catarina, Health Sciences Center, Clinical Analysis Department, Campus Universitário, Trindade, Box 476,Zip code: 88.040-900-Florianópolis, Santa Catarina, Brazil. Phone: 005548 331-9712. Fax: 005548 331-9542. E-mail: marlisouza@uniplac.net.

The Brazilian Journal of Infectious Diseases 2005;9(6):489-493 (C) 2005 by The Brazilian Journal of Infectious Diseases and Contexto Publishing. All rights reserved. and actions aimed at guaranteeing the quality of blood throughout the entire process.

HIV-1 in can be transmitted by erythrocytes, platelets, cryoprecipitate, frozen fresh plasma, and probably by other blood components. In 2000, the risk of infection per transfusion was estimated to be 1:650,000 [2]. The immunological window period for HIV is between 22 and 25 days. The higher sensitivity and specificity of current diagnostic kits is decreasing the immunological window and consequently, the residual risk, improving transfusion safety.

The residual risk of an infection depends on four main factors: sensitivity of the method, incidence, in which we must observe the need for multiple and serial donations and the existence of a great number of donations, duration of the immunological window, the smaller the immunological window the smaller the risk, and laboratorial errors, which can occur at any phase of the selection, screening and transfusion processes [4]. 
The residual risk is a product of the incidence and the period of the immunological window [5]. In a blood bank setting, the incidence is available only for repeat donors and estimations of seroconversion date may be made as a mean point between a seronegative and a seropositive donation. Seroconversion is defined as a seropositive blood donation from a donor whose previous donation had all tests susceptible to screening scored negative [6,7].

The objective of our study was to determine the rate of the residual risk for HIV I/II transmission by blood transfusion in blood donors in the Mountain Region of Santa Catarina, in the light of the new legislation concerning transfusion security.

\section{Material and Methods}

Estimates of residual risk were calculated from the results of blood assays and data obtained from donor protocols in the Regional Blood Center of Lages. In order to calculate the residual risk of HIV markers, 4,857 out of 24,969 repeat donors who had made donations between 2000 and 2003 were evaluated. This project was approved by the Human Research Ethics Committee of the Federal University of Santa Catarina - Project number 116/2003.

The incidence/window model applied in studies in the USA by Schreiber was used to estimate the residual risk, based on incidences of HIV infection among donors who made at least two donations, between January 1,2000, and December 31, 2003, and on the respective estimated window periods.

The number of incident cases is the number who gave a seronegative donation followed by a confirmed seropositive donation for one of the HIV markers. The denominator of the incidence, expressed as personyears, was calculated by summing the interval in days (divided by 365) between the first and the last donation of each donor during the study period [6,7]. The periods of the "immunological window" were derived from data (the residual risk was estimated by multiplying the incidences, expressed per person-year, by the "window period", expressed as a fraction of a year
$[6,8]$. The software used to analyze the results was Stats Direct Statistical software version 2.3.5.

\section{Results}

Four thousand eight hundred and fifty-seven repeat donors were evaluated from 2000 to 2003, with an estimated risk of 1:500,000. A case was considered confirmed when one of the HIV markers presented a positive result in two independent blood samples. If a positive blood donor, based on the markers analyzed, did not return to collect the second sample it was considered a suspect case.

Table 1 shows the residual risk for anti-HIV I/Ii in 2000 , estimated to be $1: 125,000$. In the following years of study (2001 to 2003), it was not possible to calculate the risk, since there were no seroconversion samples for this marker.

Table 2 presents the residual risk estimated for HIV and respective incidence and window periods between 2000 and 2003.

\section{Discussion}

In our study, the residual risk for HIV markers in blood donors in the Regional Blood Bank in the Mountain Region was estimated to be 1:50,000 in the period between 2000 and 2003, being considered one of the lowest rates in the state of Santa Catarina, in comparison with previous studies. However, it was higher than in developed countries, such as France, where the risk was estimated to $1: 400,000$ for HIV [9].

In the USA, Schreiber (1996), before the introduction of tests to detect the antigenemic p24 in blood donors, obtained an estimated risk of from 1 in 450,000 to 1 in 660,000 donations per year $[5,10]$.

In Brazil, the residual risk for HIV by transfusion has always been higher than in these other countries. In 1993, this risk was estimated to be between 1 in 2,533 and 1 in 15,000 transfusions made in São Paulo [11]. In a study with more than 5,000 repeat donors 
Table 1. Incident tests, seroconversion estimate and residual risk for anti-HIV in repeat blood donors from 2000 to 2003

\begin{tabular}{lcccccccc}
\hline Tests & \multicolumn{2}{c}{$\mathbf{2 0 0 0}$} & \multicolumn{2}{c}{$\mathbf{2 0 0 1}$} & \multicolumn{2}{c}{$\mathbf{2 0 0 2}$} & \multicolumn{2}{c}{$\mathbf{2 0 0 3}$} \\
\cline { 2 - 8 } & $\mathbf{N}$ & days & $\mathbf{N}$ & days & $\mathbf{N}$ & days & $\mathbf{N}$ & days \\
\hline Anti-HIV tested & 1,121 & 282617 & 1,124 & 259182 & 1,108 & 258730 & 1,128 & 282270 \\
Confirmed HIV $^{+}$ & 1 & 180 & 0 & & 0 & & 0 \\
Confirmed HIV $^{-}$ & 0 & & 0 & 1 & 195 & 0 \\
Suspected HIV $^{+}$ & 0 & & 0 & 1 & 554 & 0 \\
Estimated number & 1 & 77405 & 0 & 0 & & 0 \\
of seroconversions & & & & & & & \\
Incidence per 1000 & 1.29 & & 0 & 0 & & 0 \\
Residual risk & 0.08 & & 0 & & 0 & & 0 & \\
\hline
\end{tabular}

Table 2. Residual risk estimated for HIV markers in blood donors in the Regional Blood Center in Lages from 2000 to 2003

\begin{tabular}{ll}
\hline & Anti-HIV-I/II \\
\hline Incidence & 0.020 \\
Length of window period (days) & 22 \\
Residual risk per 1000 & 0.020 \\
Residual risk per donation & $1: 50,000$ \\
\hline
\end{tabular}

who had donated blood between 1994 and 1997 in the Blood Center in Marilia (state of SP), there was a slightly different result: the residual risk for HIV transmission was 1 in 10,330 [3]. Another study, using the same methodology, with blood donors at the Blood Bank in Riberao Preto, between 1996 and 1998 presented a residual risk of 1 in 77,000 [12]. During the same period, the Pro-Blood Foundation Blood Center of São Paulo (Fundação Pró-Sangue Hemocentro de São Paulo) estimated the residual risk of HIV infection in repeat donors to be 1:64,000 donations [13].

A study on HIV was also done by Kupek in 2001, he reported the estimated risk in the 1990s in the capital of the state of Santa Catarina, where it was observed that the risk for HIV in blood donors decreased from $1: 5,000$ in $1991-1994$ to $1: 48,777$ in $1997-1999$, similar what was found in our study in the Mountain Region in SC [14,15]. Most of these studies used the incidence/window model, however there are limitations in the methodological approach adopted and in the interpretations of the data. Firstly, there was great variation in the mean interval between donations, although a small number of donors in seroconversion was expected, they contributed to large intervals in security to incidence estimates and residual risk [16].

An underestimation can occur because the calculation does not take into account all donations, but only those from donations by repeat donors. The window period can be underestimated, since there are documented cases from transfusion- transmitted infections and they are probably differ for subjects infected by sexual contact or by infected materials, which are the main factors affecting infected blood donors [8]. 
The residual risk can be due to factors other than those associated with the window period, such as: technical and human error estimated to be 1:10,000,000 for an HIV-positive donation, variants not recognized by some assays, like HIV-1 group $\mathrm{O}$, which are extremely rare, and chronic virus carriers who have not developed antibodies and who are even rarer. Consequently, the highest risk is that linked to the window period [9].

The prevention of transmission of viral infection through blood components usually takes place through the exclusion of infected donors. Before any other procedure or assay, it remains the essential phase to guarantee the security of blood components $[8,17]$. The recruitment and selection of blood donors aims at keeping individuals with risk factors for transmission-transmitted infections from donating blood. Donations undergo systematic screening tests that make it possible for infected donations to be removed and infected donors excluded. Although these measures are taken, a risk of transmitting viral infections by the transfusion of blood components still remains. This risk, which is currently low, is associated mainly with the "window period", right after the donor is infected, before infection markers become detectable.

In order to decrease the risk, some measures were suggested, including vaccination of donors against Hepatitis B and efforts to promote health aiming at the reduction of blood-borne infectious diseases, such as, educational campaigns in order to make people aware of this problem $[14,17]$; monitoring the residual transfusion risk using the incidence window/ period, which is not expensive and is easy to calculate; and temporary introduction of new screening methods that have a short infectious window period, such as PCR in high risk areas, $[9,17]$. According to Hamerschlak (1999), there must be investments to encourage regular and conscious donations, in order to decrease the residual risk for HIV transmission [11].

The coastline of Santa Catarina leads the national ranking of the percentage of injectable drug users among AIDS patients, increasing the incidence of
Hepatitis B in the population. Educational campaigns must be implemented about the existence of the immunological window period with counseling for donor candidates,. However, in the Mountain Region of Santa Catarina, habits and customs of the population, which are considered more conservative, differ from those who live on the coast. The cold weather favors more daytime habits, since attractions and tourists are not so common as they are in coastal regions. The nightlife, which does not offer many options, favors less risky activities, such as meetings at a friend's house.

Transfusion safety depends on several factors, ranging from the contents of educational campaigns directed towards donor awareness, knowledge of and respect for rules established in the current legislation, quality programs in the transfusion area, and technical qualification of laboratory employees in the Blood Center. Improvement of the procedures for the recruitment and selection of donors can be obtained in the mid-long run, including: vaccination against Hepatitis B, projects that affect individuals outside of high-risk groups, programs to reduce the damages for injectable drug users, as well as health education about blood-borne infectious diseases in general, and the risk of transfusion in particular.

\section{Conclusions}

The significant decreases in the rates of $\mathrm{HBV}, \mathrm{HCV}$ and HIV positive donation, as well as reduced residual risk of transmission of these viruses, show the progress, in recent last years, of preventive measures for the recruitment and selection of donors before donation, and the improvement of screening tests.

The residual risk estimated for HIV in our Blood Center is one of the lowest in the state, giving values for HIV of 1:50,000, confirming the hypothesis that the new national "blood policies" legislation, due to the introduction of more sensitive tests, is decreasing the immunological window period, reducing the residual risk and consequently, increasing transfusion safety. 


\section{Acknowledgements}

We thank Professor Emil Kupek, for his valuable collaboration in the residual risk calculation. This paper is part of the Master's Degree Dissertation "Evaluation of transfusion safety by the seroepidemiological study of hepatitis B, C, HIV- I/II and cytomegalovirus in blood donors". Federal University of Santa Catarina, 2004.

\section{References}

1. Carmo R.A. Viral Hepatitis. Belo Horizonte: Fundação Centro de Hematologia e Hemoterapia de Minas Gerais. Caderno Hemominas 1996;8:57.

2. Verrastro T., Lorenzi T.F., Wendel Neto S. Hematology and hemotherapy: foundations of morphology, physiology, pathology and clinics. São Paulo: Atheneu, 2002. 303 p.

3. Canutti Junior V. Tranfusional Risk: methodology and study. Update in Hemotherapy 1998;5:90-9.

4. Specific Laboratorial Diagnostics. Hepatitis. In: Veronesi, R; Focaccia, R. Tratado de Infectologia. $2^{\mathrm{a}}$ ed. São Paulo: Ateneu, 2002.

5. Schreiber G.B., et al. The risk of transfusion - transmitted viral infections. The New England Journal of Medicine 1996;(26):334.

6. Pillonel J., et al. Trend in residual risk of transfusiontransmitted viral infections in France between 1992 and 2000. Transfusion 2002; 42:980-8.

7. Korelitz J.J., et al. A method for estimating hepatitis B virus incidence rates in volunteer blood donors. Transfusion 1997;37:634-40.

8. Muller-Breitkreutz K.T., Evers.T., Perry R. Viral marker rates among unpaid blood donors in Europe decreased from 1990 to 1996. Euro surveillance 1998;3(7).

9. Pillonel C., Saura A.M. Viral marker rates among unpaid blood donors in Europe decreased from 1990 to 1996. European Communicable Disease Bulletin. Euro surveillance. V. 03 N. 7 July 1998. Available at: http:// www.eurosurveillance.org/em/v03n07/v03n07.pdf. Accessed June 8, 2004.

10. Fernandes M.L.C., et al. Reinvestigação de casos de aids classificados na categoria de exposição transfusão no SINAN/AIDS, Brasil 1999/2000. Available at: <http:// www.aids.gov.br/final/biblioteca/bol_dezembro_2002/ artigo1.asp> Accessed May 20, 2004. Ministério da Saúde - Coordenação Nacional de DST e AIDS Ministério da Saúde.
11. Hamerschlak N., Pasternak J., Neto V.A. Today's risk for AIDS transmission by transfusion. Rev Hosp Clin Fac Med S Paulo 1993;48(4):183-5.

12. Covas D.T. Transmission Risk for HIV-1 by blood transfusions. Escola Brasileira de Hematologia. Série de Monografias 1998;5:100-6.

13. Sabino E.C., Salles N., Sáez-Alquézar A., et al Estimated risk of transfusion-transmitted HIV infection in São Paulo, Brazil. Transfusion 1999;39:1152-3.

14. Kupek E.J. The reduction of HIV transfusion risk in southern Brazil in the 1990s. Science Ltd. Transfusion Medicine, Blackwell, p. 75-78, 2001.

15. Souza M.A. Evaluation of transfusion safety by the seroepidemiological study of hepatitis B, C, HIV- I/II and cytomegalovirus in blood donors". Master's Degree Dissertation. Federal University of Santa Catarina - UFSC, Florianópolis, 2004.

16. Kupek E.J. Time trends in seroprevalence for HIB, Syphilis and Hepatitis B and C in blood donors in the Great Region in Florianopolis (1991- 1996). J Bras Patol 2001;37: 17-23.

17. Chiavetta J.O. A., et al. Incidence and estimated rates of residual risk for $\mathrm{HIV}$, hepatitis $\mathrm{C}$, hepatitis $\mathrm{B}$ an human T-cell lymph tropic viruses in Blood donors in Canada, 1990-2000. Research CMAJ 2003;8:169.

18. Centro de Hematologia e Hemoterapia do Estado de Santa -HEMOSC. Relatório do HEMOPROD, 2003. Available at: <www.hemosc.org.br/ HEMOPROD> Accessed November 16, 2003. 